\title{
Corrosion Behavior and Mechanical Properties of Rebar HPB235
}

\author{
Ying Wang
}

Department of Civil Engineering, Luoyang Institute of Science and Technology, Luoyang, China e-mail: eappol@126.com

Keywords-rebar; corrosion; strength; elongation

\begin{abstract}
The corrosion behavior of rebar HPB235 in $1.5 \mathrm{wt} . \% \mathrm{NaCl}$ solution was studied, and the mechanical properties before and after corrosion were tested. The results showed that, with the increase of corrosion time from 240h to 720h, the corrosion rate of rebar HPB235 increases and the corrosion becomes heavier. After corrosion for $720 \mathrm{~h}$, the yield strength and tensile strength are decreased by more than $5 \%$, but the elongation is increased by less than $5 \%$.
\end{abstract}

\section{Introduction}

As the most common modern building structure, rebar concrete has been widely used in many fields. The high alkaline concrete pore solution usually provides a protective environment for the rebar in the concrete. A layer of protective film is formed on the rebar, and reduces or restrains its corrosion [1-5]. Nevertheless, with the passage of time and the change of environment, the inrush of chloride and the carbonization of concrete cause the corrosion of rebar, which results in the concrete weakening and thereby continuous engineering accidents. Therefore, the corrosion of rebar has been one of the main factors to cause the failure of concrete structures [6, 7].

However, in designing a concrete structure, the corrosion of rebar is seldom considered and the excellence of concrete is not brought into action in service period. The damage of rebar corrosion is increasingly attaching more and more attention, and the research on rebar corrosion and its effect on the mechanical properties of rebar is increasing [8-12]. In this paper, the corrosion behavior of rebar HPB235 in concrete structure in simulated concrete pore solution is studied, and its mechanical properties before and after corrosion are tested. It is hoped to provide help to prolong the lifespan of rebar and enhance the duration of concrete structure.

\section{Experimental}

The test samples are cut from normal rebar HPB235. They have two sizes: short samples $(\Phi 14 \mathrm{~mm} \times 20 \mathrm{~mm})$ used for corrosion morphology observation and corrosion scale analysis, and long samples $(\Phi 14 \mathrm{~mm} \times 450 \mathrm{~mm})$ used for corrosion rate measuring and mechanical properties tests. Before corrosion, the samples are polished, cleaned, and rust-removed, and weighed by an electron balance. The mechanical properties, including yield strength, tensile strength and elongation, are tested by a hydraulic pressure universal testing machine.

The corrosion media is simulated pore solution in concrete structure, and its composition is saturated $\mathrm{Ca}(\mathrm{OH}) 2$ solution with $1.5 \mathrm{wt} . \% \mathrm{NaCl}$. The corrosion time is 10,20 and 30 days, i.e. 240h, 480h and 720h. After corrosion, different treatments are carried out for different samples: for short samples, corrosion morphology observation and corrosion scale analysis are made by a scanning electron microscope (SEM, JSM-5610LV) after they are cleaned and dried out; for long samples, corrosion rate calculation and mechanical properties tests are made after they are immersed in thin hydrochloric acid to remove the rust on the surface. 


\section{RESULTS}

\section{A. Corrosion rate}

The measuring results of corrosion rates of rebar HPB235 in $1.5 \% \mathrm{NaCl}$ solution are given in Table 1. It can be seen that, with the increase of corrosion time from $240 \mathrm{~h}$ to $720 \mathrm{~h}$, the corrosion rate (weight loss rate) increases from $0.07 \%$ to $0.21 \%$. It also can be seen that, the corrosion rate has linear relationship with the corrosion time between $240 \mathrm{~h}$ and $720 \mathrm{~h}$.

Table 1 Corrosion rates of rebar HPB235

\begin{tabular}{|c|c|c|c|c|c|}
\hline & Mass & \multicolumn{3}{|c|}{ Mass after } & Corrosi \\
N & before & \multicolumn{3}{|c|}{ corrosion [g] } & on \\
o. & corrosion \\
\cline { 3 - 5 } & [g] & $\mathbf{2 4 0 h}$ & $\mathbf{4 8 0}$ & $\mathbf{7 2 0 h}$ & $\begin{array}{c}\text { rate } \\
{[\%]}\end{array}$ \\
\hline 1 & 467.85 & 467. & - & - & 0.07 \\
& & 51 & & & \\
\hline 2 & 476.01 & - & 475. & - & 0.14 \\
\hline 3 & 496.50 & - & - & 495.4 & 0.21 \\
\hline
\end{tabular}

\section{B. Corrosion morphology}

The SEM observing results of corrosion morphologies of rebar HPB235 in $1.5 \% \mathrm{NaCl}$ solution are showed in Fig. 1. It can be seen that, with the increase of corrosion time, the character of corrosion morphology is changed. At 240h, the corrosion is slight and uneven in different areas, and a small quantity of corrosion scale is on the surface (see Fig.1a). At 480h, the corrosion is still uneven, but much heavier in level. The quantity of corrosion scale is a little more (see Fig.1b). At $720 \mathrm{~h}$, the corrosion is uniform (see Fig.1c). In view of the overall situation, with the corrosion time between $240 \mathrm{~h}$ and $720 \mathrm{~h}$, the corrosion develops from the subdomain to total surface, and becomes heavier and heavier. The corrosion turns from local corrosion into overall corrosion, and the corrosion rate becomes higher and higher. The results are basically conformance with the corrosion rates in Table 1.

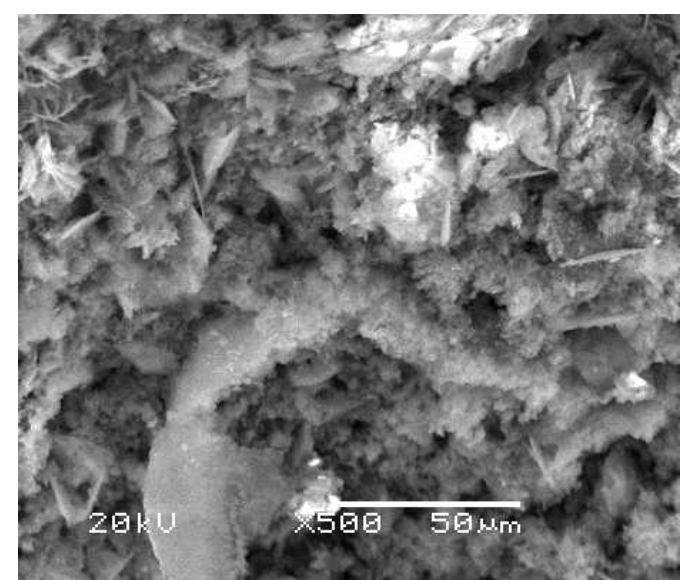

(a) $240 \mathrm{~h}$ 


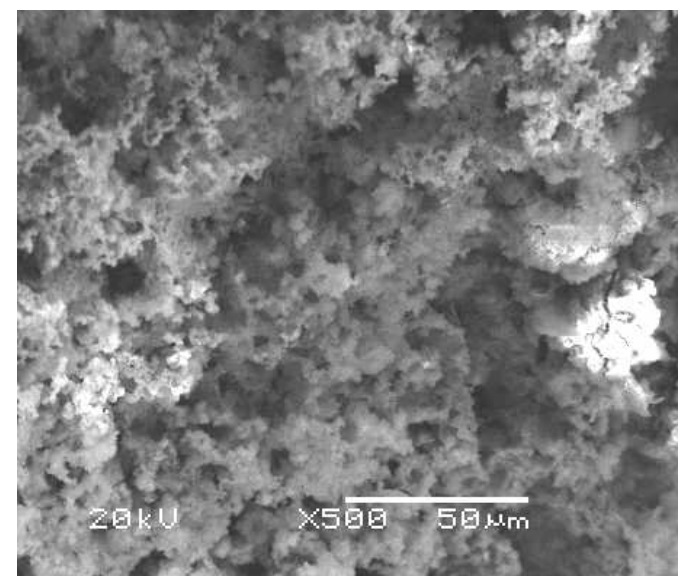

(b) $480 \mathrm{~h}$

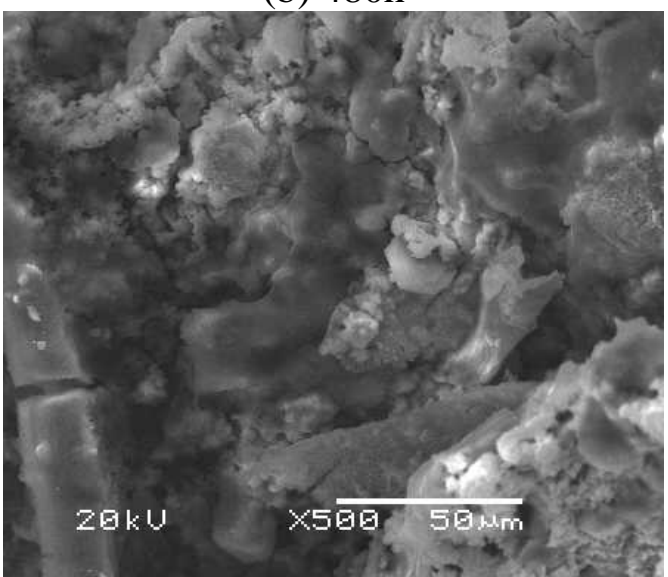

(c) $720 \mathrm{~h}$

Figure 1 Corrosion morphologies of rebar HPB235

\section{Corrosion scale}

The EDS analysis results of corrosion scales of rebar HPB235 in $1.5 \% \mathrm{NaCl}$ solution are given in Figure 2. It can be seen that, at 240h-720h, the corrosion scale on rebar is made up of two elements Fe and $\mathrm{O}$. With the increase of corrosion time, the variation of their mass or atom percent is not obvious. It is presumed that, in the present work, the corrosion products of the steel are mainly composed of Fe oxides (Fe2O3, Fe3O4 or both).

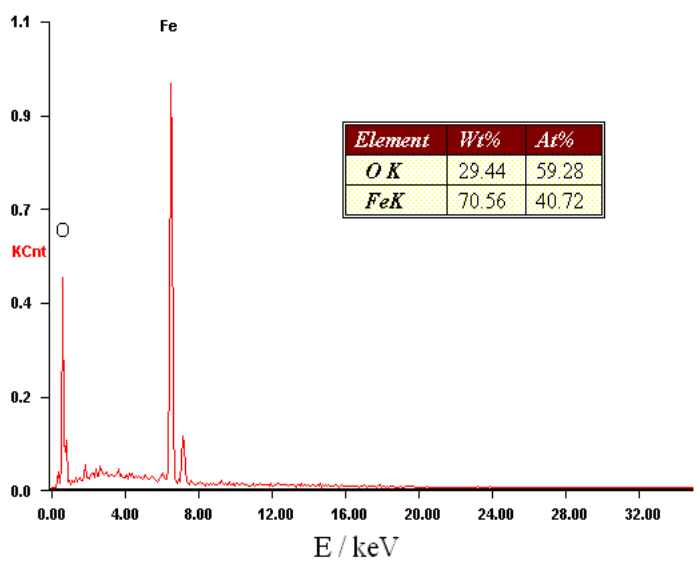

(a) $240 \mathrm{~h}$ 


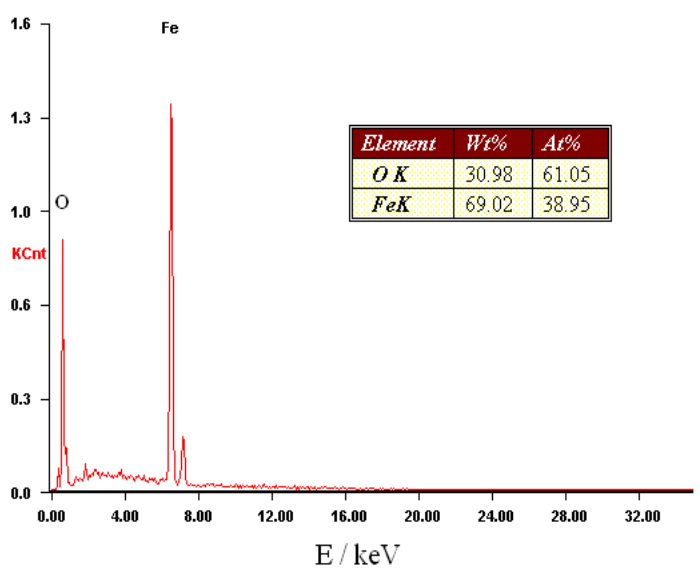

(b) $480 \mathrm{~h}$

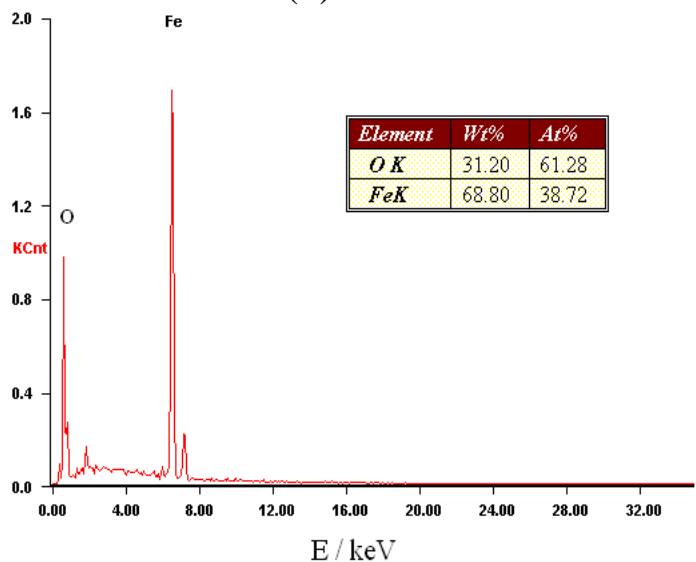

(c) $720 \mathrm{~h}$

Figure 2 EDS results of corrosion scales of rebar HPB235

\section{Mechanical properties}

The measuring results of mechanical properties of rebar HPB235 before and after corrosion in $1.5 \% \mathrm{NaCl}$ solution are given in Table 2. It can be seen that, after corrosion for $720 \mathrm{~h}$, the variation of each mechanical property is not the same. The variation of yield strength and tensile strength are relatively large, and the rates of descent are more than $5 \%$ (6.77\% and $11.61 \%$ respectively). The variation of elongation is very different, and the rate of increase is less than $5 \%(3.51 \%)$. A preliminary analysis suggests that the effect of corrosion on each mechanical property is different. The detailed reasons require further research.

Table 2 Mechanical properties of rebar HPB235

\begin{tabular}{|c|c|c|}
\hline $\begin{array}{c}\text { Mechanical } \\
\text { property }\end{array}$ & $\begin{array}{c}\text { Before } \\
\text { corrosion }\end{array}$ & $\begin{array}{c}\text { Corrosion } \\
\text { for 720h }\end{array}$ \\
\hline $\begin{array}{c}\text { Yield } \\
\text { strength } \\
\text { [MPa] }\end{array}$ & 310 & 289 \\
\hline $\begin{array}{c}\text { Tensile } \\
\text { strength } \\
\text { [MPa] }\end{array}$ & 422 & 373 \\
\hline $\begin{array}{c}\text { Elongation } \\
\text { [\%] }\end{array}$ & 35.7 & 37.0 \\
\hline
\end{tabular}




\section{Analysis and discussion}

\section{E. Corrosion of rebar}

In fact, the corrosion of rebar in concrete structure is an electrochemical process. Its principle is as same as that of natural corrosion of iron and steel in the air, solution, and soil. It is still an oxidation-reduction reaction in essence. It is carried out at the same time through anodic reaction (oxidation reaction) and cathodic reaction (reduction reaction) respectively.

When there is water on the surface of rebar, Fe ionizes in the anode and oxygen reduces in the cathode in the solution. The reactions occur at same rate, and their equations are as follows:

$$
\begin{gathered}
\mathrm{Fe} \rightarrow \mathrm{Fe}^{2+}+2 \mathrm{e}^{-} \\
\mathrm{O}_{2}+2 \mathrm{H}_{2} \mathrm{O}+4 \mathrm{e}^{-} \rightarrow 4 \mathrm{OH}^{-}
\end{gathered}
$$

The whole corrosion process is combination of anodic reaction and cathodic reaction. As a result of this, $\mathrm{Fe}(\mathrm{OH}) 2$ is formed on the surface of rebar, and $\mathrm{Fe}(\mathrm{OH}) 3$ is further produced by oxidation. The reactions can be written as follows:

$$
\begin{gathered}
2 \mathrm{Fe}+\mathrm{O}_{2}+2 \mathrm{H}_{2} \mathrm{O} \rightarrow 2 \mathrm{Fe}^{2+}+4 \mathrm{OH}^{-} \rightarrow 2 \mathrm{Fe}(\mathrm{OH})_{2} \\
4 \mathrm{Fe}(\mathrm{OH})_{2}+\mathrm{O}_{2}+2 \mathrm{H}_{2} \mathrm{O} \rightarrow 4 \mathrm{Fe}(\mathrm{OH})_{3}
\end{gathered}
$$

And the next step is the formation of $\mathrm{nFe} 2 \mathrm{O} 3 \cdot \mathrm{mH} 2 \mathrm{O}$ (red rust) and $\mathrm{Fe} 3 \mathrm{O} 4$ (black rust), and a layer of rust is formed on the surface of rebar. The volume of red and black rust is increased as four and two times as that of original one respectively. The increased volume of rust produces pressure to the surrounding concrete, causes the concrete crack along the rebar, and leads to the drop of protective layer in pieces. The formation of crack and the drop of the protective layer result in the further heavier corrosion of the rebar, which will lead to the decrease of mechanical properties of rebar.

\section{F. Mechanical properties of rebar after corrosion}

The results of yield strength and tensile strength of rebar HPB235 before and after corrosion are shown in Table 2. It can be seen that, the yield strength and tensile strength of rebar after corrosion are less than those before corrosion. The reasons can be analyzed from the macro and micro aspects.

From the macro perspective, there are two main reasons for the decrease of yield strength and tensile strength: First, the rebar produces weight loss after corrosion, and the effective section area is smaller, which decrease the tensile force that it can resist. Second, the surface of rebar becomes uneven after corrosion, and the stress concentration is serious, which causes further decrease of the tensile force that it can resist.

From the micro perspective, corrosion is an electrochemical reaction in the surface of rebar, and turns iron and steel material into rust, which changes the surface and the microstructure. At the same time, the corrosion also changes the internal structure due to the existence of the inner stress. These will affect the strength properties of rebar.

The results of elongation of rebar HPB235 before and after corrosion in $1.5 \mathrm{wt} . \% \mathrm{NaCl}$ solution are shown in Table 2. It can be seen that, the variation of elongation is quite different from that of yield strength and tensile strength. When corrosion time is $720 \mathrm{~h}$, the elongation increases.

In general, the elongation of rebar decreases after corrosion because the plasticity becomes poor. The reason is that plastic deformation mainly focuses on the most serious corrosion section where the section loss is the largest and the crack occurs. Many experimental results have proved it. But the result in this work is not so.

According to Table 2, combined with the results of corrosion rate in Table 1, it can be drawn that the elongation of rebar does not decrease after corrosion for 720h. However, the corrosion rate is not the decisive factor to decrease the elongation of rebar. With increasing corrosion rate, the elongation is not always lower, and it can even increase after corrosion.

According to the above analysis, the dominant corrosion type of the rebar is different at different time. The severity of stress concentration after corrosion is also different. This should be one of the main reasons to cause the fluctuation of elongation. 
When the corrosion rate is same, uniform corrosion reduces less section area than local corrosion, and the stress concentration is less adverse. Though the load it can afford is lower (the yield strength and tensile strength decreases), the rebar becomes thinner in the whole, and no obvious weak positions appear. The rebar is more difficult to crack than that under local corrosion (especially pit corrosion), so it can afford more plastic deformation, and the elongation may increase.

\section{Conclusions}

With the increase of corrosion time from $240 \mathrm{~h}$ to $720 \mathrm{~h}$, the corrosion rate of rebar HPB235 increases and the corrosion becomes heavier and heavier in $1.5 \mathrm{wt} \% \mathrm{NaCl}$ solution, but the corrosion scale is not changed obviously in compositions.

After corrosion for 720h, the yield strength and tensile strength of rebar HPB235 are decreased by more than $5 \%$, but the elongation is increased by less than $5 \%$.

\section{Acknowledgment}

The financial support of Basic and Frontier Technologies Research Plan of Henan Province in China (No. 122300410348) is gratefully acknowledged.

\section{References}

[1] P. Li, D.X. Zhang, Corrosion and protection of reinforcing steel in concrete structure, Materials Protection. vol. 43, 2010, pp. 44-46. (in Chinese)

[2] P. Li, Y. Wang, Mechanical properties of rebar HRB400 after corrosion, Advanced Materials Research. vol. 753-755, 2013, pp. 516-519.

[3] Y. Wang, P. Li, H.M. Ning, Application of epoxy-coated reinforcing steel in concrete structure, Hot Working Technology. vol. 39, 2010, pp. 133-135. (in Chinese)

[4] Y. Wang, P. Li, Corrosion behavior of reinforcing steel bar HPB235 in NaCl solution, Advanced Materials Research. vol. 287-290, 2011, pp. 738-741.

[5] Y. Wang, P. Li, Effect of corrosion on mechanical properties of reinforcing bar HPB235, Advanced Materials Research, vol. 450-451, 2012, pp. 201-204.

[6] Z.L. Lu, Corrosion behavior and mechanism of reinforced steel in acidic environment, Journal of Chinese Society for Corrosion and Protection. vol. 27, 2007, pp. 119-123. (in Chinese)

[7] Y.X. Guo, J.X. Gong, Experimental study on corrosion of rebar, Corrosion Science and Protection Technology. vol. 19, 2007, pp. 218-220. (in Chinese)

[8] Y. Wang, P. Li, Effect of corrosion on mechanical properties of rebar HRB335, Advanced Materials Research. vol. 753-755, 2013, pp. 539-542.

[9] S.H. Yang, L. Zeng, Research of the influence of corrosion for mechanical property of reinforcing bars, Journal of Zhengzhou University (Engineering Science). vol. 26, 2005, pp. 85-88. (in Chinese)

[10] L. Zeng, S.H. Yang, Y. Zhang, Research of the mechanical property of corrosion reinforcing bars, Henan Science. vol. 23, 2005, pp. 877-879. (in Chinese)

[11] G.X. Ruan, G.Y. Liu, Governance of rebar corrosion in concrete structure, Sichuan Building. vol. 26, 2006, pp. 83-86. (in Chinese)

[12] C. Gui, Experimental research of mechanical performance of corroded reinforcement, Shanxi Architecture. vol. 33, 2007, pp. 161-162. (in Chinese) 